\title{
Surgical Treatment of Cystic Swellings of Scrotum and its Management: A Clinico-Pathological Study
}

\author{
Jasvinder Singh ${ }^{1}$, Amrit Pal Singh ${ }^{2}$ \\ ${ }^{1}$ Associate Professor, VAMC, Shahjahanpur, Uttar Pradesh, India, ${ }^{2}$ SR, Urology, Mahatma Gandhi Medical College and Hospital, Jaipur, India.
}

\section{Abstract}

Background: The treatment of cystic swellings of scrotum are one among the common surgical problem in all age group. Objective of this study is to spot the cause, mode of presentation, various modalities of treatment and outcome of these with mimnimal complications. Subjects and Methods: A total of 110 cases of cystic swellings of scrotum fulfilling the methodology criteria's were subjected to preformatted study. Final diagnosis was made with Clinical examination and Ultrasound. All 110 cases were treated surgically. Results: Most of the patients were in age group of 20-75 years, presenting feature being scrotal swelling as a main complaint in $60 \%$ of cases, majority of them were right sided (64\%), majority of them presented with in a year, $40 \%$ presented with in first 6 months and $30 \%$ in next 6 months. Primary hydrocele was the commonest cystic swelling (60\%), followed by epididymal cyst, sebaceous cyst, haematocoele, pyocoele. Lord's plication was the procedure, which was associated with early discharge of the patient and least post-operative complications. Most of the patients were discharged around 8th Post-operative day. Conclusion: Primary hydrocoele was the commonest cystic swellings of scrotum. Most of the cystic swellings were treated surgically with good results. Lord's plication procedure was the least to have post-operative complication.

Keywords: Epididymal cyst, Hydrocoele, Haematocoele, Lord's plication, Pyocoele, Spermatocoele.

Corresponding Author: Dr. Jasvinder Singh, Associate Professor, VAMC, Shahjahanpur, Uttar Pradesh, India.

Received: March 2019

Accepted: April 2019

\section{Introduction}

Treatment of simple hydroceles or cystic swellings of sccrotum is sometimes needed if they generate troublesome symptoms of pain and uneasiness. Conventional treatments include repeated aspiration and injection of sclerosant or surgery. The swellings of the scrotum are a common surgical problem. The physical well-being of the patient have been affected by the scrotal swellings and presents as diverse etiology. Clinical examination and self-examination of scrotum is simple as it is placed outside the lower abdomen and hence easily accesible. The range consists of hydrocoele, epididymal cysts, spermatocoele, haematocoele, pyocoele, and sebaceous cysts.

Cystic swelling of scrotum can achieve a very big size without causing much uneasiness to patient as it is usually painless. The mortality rate is insignificant in this condition. Due to their hanging down position the scrotum is likely to traumatic injury. The abnormal collection of serous fluid in some part of the processus vaginalis, usually the tunicais called as hydrocoele it is divided into two parts simple which is scrotal and communicating. ${ }^{[1]}$

Epididymal cysts is characterized by the cystic deterioration of the epididymis. ${ }^{[2]}$ From either the vasa efferentia of the testes or from the epididymis a retention cyst known as spermatocoele arises. ${ }^{[3]}$ The scrotum has copious amount of sebaceous glands, which may become obstructed and infected forming sebaceous cysts.

One of the sites for folliculitis is scrotum due to presence of hair follicles etc. Secondary to disease of the testes and epididymis secondary hydrocoele arise and its management consists of treatment of the principal cause.

In some tropical countries where the Wuchereria Bancrofti a parasite is endemic, filarial hydrocoele and chylocoele account for up to eighty percent of hydrocoele. Signs for treatment comprises pain, discomfort, and the cosmetic exterior of the scrotum. ${ }^{[4]}$

Conventional treatments for primary hydrocoele, epididymal cyst, and spermatocoele comprises of frequent aspiration, aspiration and injection of sclerosant or surgery. Aspiration and injection of sclerosant can cause severe pain, and recurrent aspiration bear risk of infection and haematoma formation. ${ }^{[5]}$ The surgical extirpation of the cystic lesion remains the gold standard against the conventional treatment. ${ }^{[6]}$

There is no precise treatment for secondary hydrocoele. Management of this condition consists of treatment of the fundamental cause. Surgical treatment of idiopathic hydrocoele includes 4 basic techniques Lord's plication, ${ }^{[7]}$ Winkelmann's partial excision and eversion of the sac, Jaboulay's eversion of the sac and Radical excision of the sac. Recent faster operations in adult consists of the window operations or vaginal operations. ${ }^{[7-11]}$ 
Congenital hydrocoele are treated by herniotomy. Treatment of epididymal cyst and spermatocoele consists of the excision of the cysts. ${ }^{[2,3]}$

The difficulty during operations on the scrotum are bleeding, injury to the cord structures, torsion of testes due to imperfect reposition. The common post-operative complications including haematoma and odema which can be prevented by meticulous haemostasis and post-operative scrotal support.

Because of diverse etiology, their mode of presentation and management is exclusive for each. With this background, a clinical study of cystic swellings of the scrotum was undertaken. The present study includes the review of literature regarding the classification, etiology, clinical presentation and management of cystic scrotal swellings.

\section{Subjects and Methods}

The study was done in Department of Surgery, Teerthanker mahaver Medical College and Hospital and Research centre moradabad from June 2016-november 2018, which included 100 admitted cases in different surgical units picked randomly and study was conducted as per the proforma.

Patients of all age groups who are presenting with cystic swelling in scrotum, Cystic swellings from the testes and its coverings, epididymis, spermatic cord and from scrotal skin with informed consent for the proposed surgery were included and the patients with presenting testicular tumors and patients with Epididymo Orchitis will be excluded.

\section{Method of collection of data}

Through a proforma patients admitted with symptoms of swelling, pain, discomfort in the scrotal region were studied with facilities available in the hospital,

Detailed history taking

Clinical examination

Routine laboratory investigations

Ultrasound in all cases

Performing the surgery for the cases, noting the findings

Postoperative course and management of postoperative complications

Finally follow up was done.

A total of 100 cases were included in the study of which all cases underwent surgical involvement for the disease.

According to the patient's condition surgical procedure was done and in few cases corrugated drain was used Pos Scrotal support was given in most of the cases postoperatively. The patient was told for the obligation of the follow up to the outpatient department after the discharge.

\section{Results}

Present study includes 110 cases, admitted to Department of Surgery, Teerthanker mahaver Medical college and Hospital and Research centre moradabad ,from June 2016-november 2018, The youngest patient was three year old and the oldest was seventy five years. Maximum number of cases was seen in the age group between $31-40,38$ cases accounting for $38 \%$ of cases; followed by $21-30$ age group and 31-40 age group, 24 cases each accounting for $24 \%$ of cases. Minimum number of cases are seen in the age group of 51-75, 6 cases accounting $6 \%$.

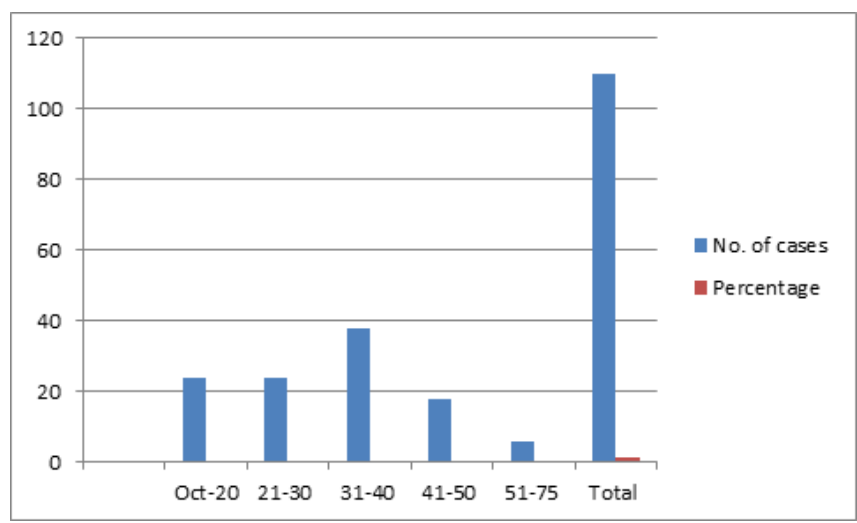

Figure 1: Age incidence of the cystic swellings of the scrotum.

Table 1: Aetiology of cystic swellings of scrotum.

\begin{tabular}{|l|l|l|}
\hline Aetiology & $\begin{array}{l}\text { No. of } \\
\text { cases }\end{array}$ & Percentage \\
\hline Primary vaginal hydrocoele & 70 & $70 \%$ \\
\hline Epididymal cyst & 28 & $28 \%$ \\
\hline Sebaceous cyst & 4 & $4 \%$ \\
\hline Haematocoele & 4 & $4 \%$ \\
\hline Pyocoele & 2 & $2 \%$ \\
\hline Spermatocoele & 2 & $2 \%$ \\
\hline Total & 110 & $110 \%$ \\
\hline
\end{tabular}

Primary vaginal hydrocoele was the commonest cause of cystic swellings 70 of 100 cases accounting for $70 \%$ of the study, followed by epididymal cyst, 28 cases accounting for $28 \%$. 4 cases of haematocoele were noted and 4 cases of Sebaceous cyst of which 2 was multiple sebaceous cyst. 2 cases each of spermatocoele and pyocoele.

Table 2: Different surgical procedures employed for treatment of swellings.

\begin{tabular}{|l|l|l|}
\hline Procedure & $\begin{array}{l}\text { No. of } \\
\text { cases }\end{array}$ & Percentage \\
\hline Lord's Plication & 50 & $50 \%$ \\
\hline Eversion of sac & 20 & $20 \%$ \\
\hline Excision & 34 & $34 \%$ \\
\hline Evacuation of clot and eversion & 4 & $4 \%$ \\
\hline Incision and drainage & 2 & $2 \%$ \\
\hline Total & 110 & $110 \%$ \\
\hline
\end{tabular}

Primary vaginal hydrocoele was treated by Lord's plication in 50 cases, Eversion of sac in 20 cases. Epididymal cyst, spermatocoele, and sebaceous cyst were excised accounting for 34 cases, of which 2 cases of multiple sebaceous cyst was treated by excision of skin and primary suturing. Evacuation of clot and eversion were done in 4 cases of haematocoele. Incision and drainage for pyocoele in 2 cases.

Pain was present postoperatively in all cases. Scrotal edema was seen in 22 cases (22\%), Scrotal edema was least in 
Lord's Plication, when compared to other procedure for vaginal hydrocoele. Haematoma was seen in 6 cases $(6 \%), 4$ cases post eversion of sac, 2 cases in post epididymal cyst excision, and 4 cases in Evacuation of clot and Eversion of sac.

Table 3: Post-operative complications in the present study with relation to the surgical procedure.

\begin{tabular}{|l|l|l|l|l|l|}
\hline Procedure & No. of Cases & Pain & Scrotal Oedema & Haematoma & Wound Infection \\
\hline Lord's Plication & 50 & 50 & 4 & 0 & 0 \\
\hline Eversion of sac & 20 & 20 & 10 & 4 & 4 \\
\hline Excision & 34 & 34 & 3 & 4 & 0 \\
\hline Evacuation of clot and & 4 & 4 & 2 & 2 & 0 \\
\hline Eversion of sac & 2 & 2 & 1 & 0 & 1 \\
\hline Incision and Drainage & 2 & 110 & 20 & 10 & 5 \\
\hline Total & 110 & & \\
\hline
\end{tabular}

\section{Discussion}

Cystic swellings of the scrotum are a common surgical problem. Present study includes 110 cases with cystic swellings of scrotum, admitted to Department of Surgery, Teerthanker mahveer medical college and hospital, moradabad. Most of the patients were in age group of 31-40 years $(38 \%)$, presenting feature being scrotal swelling as a main complaint in $60 \%$ of cases, majority of them presented with right sided swelling accounting 64\%, majority of the swelling showed duration of symptoms within 6 months, accounting for $40 \%$ of the cases. However, many other had scrotal swelling with pain or pain alone as a complaint, few presented with fever.

Primary vaginal hydrocele was the commonest cystic swelling $(70 \%)$, followed by epididymal cyst. Primary hydrocele is idiopathic in origin, haematocele follow recent trauma and pyocele was secondary to infection of hydrocele.

On examination, skin rugosity loss was seen on the affected side in majority of patients with swelling, cystic and fluctuant. Transillumination was positive in most of the cases, however longstanding hydrocoele had few transillumination negative. Spermatocoele, haematocoele and pyocoele were transillumination negative. Hydrocoele was more common on the right side than left side, this observation is with respect to study done by Mahalingam $\mathrm{C}$ and Boukinda F. ${ }^{[12,13]}$ After scrotal examination, the diagnosis was confirmed by scrotal ultrasonography in relevant cases.

Routine investigations were done for all cases. Surgical treatment was carried out in all 110 cases. Spinal anaesthesia was used in most of the cases, however General anaesthesia was used in younger age group and one failed case of spinal anaesthesia. Excisions of sebaceous cyst and epididymal cyst in few cases was done under local anaesthesia using 2\% xylocaine and Midazolam. Lord's plication was the procedure found most effective, simple and carried least complication rate than any other procedure for hydrocoele. Agarwal OP did a comparative study on radical cure of hydrocele. In this study, he showed that among 50 cases who were operated by Lords Placation, none of them developed haematoma or infection, where as in 50 cases who underwent, eversion of sac 14 (28\%) cases developed haematoma and $8(16 \%)$ cases developed infection. In our study, among 20 cases underwent eversion of sac no case developed haematoma and 1 case developed wound infection, where as in Lords Plication none of them had haematoma and wound infection except 4 cases, which had scrotal edema.

This study shows that for hydrocele Lords Plication, is simple, effective, safe and economical. It is the procedure of choice for management of small to moderte sized primary hydrocele. The only factor against to this procedure is a large hydrocele or a thick walled hydrocoele, where eversion of sac is the operation of choice. The postoperative complication apart from pain, which was common in all patients was some sequelae, scrotal odema was found in 11 patients and haematoma post operatively in 3 cases, This was the result of sac separation and dissection. This was least in Lord's plication, because procedure avoids the opening of the cleavage between the sac and surrounding tissue, thus reducing the oozing and subsequent haematoma formation and thus less post op complication and early discharge from the hospital. However, this procedure is barred in long standing large hydrocoele with thick sac, where in eversion of sac was chosen.

Epididymal cyst was the second most common cystic swelling treated by excision few were done under local and were discharged within 5 days. Similarly, spermatocoele was seen in one patient was treated by excision. Haematoma was treated by evacuation and eversion of the sac. Pyocoele was treated by Incision and Drainage and under suitable antibiotics. Drain was kept as per the decision by the surgeon in few cases and was removed within 24-48 hours. All the cases were given tight scrotal support and appropriate antibiotics and analgesics, it helps to relieve pain, reduces edema and haematoma. Postoperative complications were managed conservatively with antibiotics, analgesics and scrotal support Hydrocoele fluid was amber coloured in primary vaginal hydrocoele, clear in epididymal cyst, haemorrhagic fluid was seen in two caseshaematocoele. Most of the patient was discharged between 6-10 days. but some patients who developed scrotal edema and infection were kept till 11-15 days.

Patients were then followed up for 2-4 months, there was no recurrence of lesion in the patients followed up during this period. Limitations of this study was, study does not include inguinoscrotal swellings like, Congenital hydrocoele, Funicular hydrocoele, Filarial hydrocoele, Infantile hydrocoele. Most of the patients are from rural setup, illiteracy and ignorance was the problem in follow-up of the patients. 


\section{Conclusion}

Majority of the patients with cystic swelling of the scrotum belonged to the 31-40 years of age group, followed by 1120 years and 21-30 years of age group. Scrotal swelling was the common mode of presentation. Right side was dominant side of presentation than the left with a difference of $40 \%$. Most of the patients were suffering with symptoms of duration 0-6 months .Primary vaginal hydrocoele was the commonest cause of cystic swelling of scrotum. Primary hydrocele of long duration can produce pressure effects on the testis. Lord's procedure carried least complication and less postoperative stay than any other procedure in treatment of primary hydrocoele. Minimal dissection of the tissues during surgery and good haemostasis are the key to pevent post-operative complications. Postoperative stay duration, average was 8 days. There was no recurrence of lesion in the patients followed up during 2-4 months.

\section{References}

1. Fowler C. The Testes and Scrotum. Chapter 79. In: Bailey and Love's Short Practice of Surgery, Norman S Williams, Christopher J K Bulstrode, Connell PRO. (eds). 25th Edition, London: Arnold publishers; 2008; 1377-1416.

2. Goldstin M. Surgical Management of Male infertility and other Scrotal disorder. Vol. I. In: Campbell's urology, Patrick C. Walsh, Alan B Retik Vaughan(eds). 8 edition. Edinburgh: WB Saunders Company; 2002:313-316.

3. Margaret. Surgery of the groin and external genitalia. In: Farquharsons's Text book of Operative general surgery, Farquharson M, Morgan B Hodder (eds). 9th edition. Edinburgh: Arnold Publishers;
2004:474.

4. $\mathrm{Ku} \mathrm{JH}$. The Excision, Plication and Internal drainage techniques-a comparison of the results for idiopathic Hydrocoele. Br J Urol Internat. 2001;87:82-4.

5. Lavelle MA. Surgical treatment of cystic swellings of scrotum under local anaesthesia. England. Ann Royal College Surg. 1996;78:541-3.

6. Courtney SP, Wightman J. Sclerotherapy for scrotal cysts using tetracycline instillation. Edinburgh: J Royal College Surg. 1991;36:103-4.

7. Rodriguez WC, Rodriguez DD. The operative treatment for hydrocoele - a comparison of 4 basic techniques. J Urol. 1981;125:804-5.

8. Lord PH. A Bloodless operation for the radical cure of idiopathic hydrocoele. British Journal of Surgery 1964; 51:914-916.

9. Olumi AF, Richie JP. Urol Surg. Vol. II. In: Sabiston Textbook of Surgery - The Biological Basis of Modern Surgical Practice, Courtney M Townsend, R.Daniel Beauchamp , B.Mark Evers, Kenneth Mattox L (eds). 18th Edition. Edinburgh W.B. Saunders Company; 2004;2272-2273.

10. Nigam UK. Window operation - New technique for Hydrocoele. Br J Urol Internat. 1984;24:481-2.

11. Falandry L. A simple alternative technique in the treatment of idiopathic hydrocoele in adult-Vaginal fenestration. Prog Urol. 1995;5:568-74

12. Mahalingam. Prevalence of hydrocoele in rural population. Indian J Surg. 1985;413-414.

13. Boukinda F. Vaginal hydrocoele. Report of 55 surgically treated cases. Ann Urol. 2003;37:293-5.

14. Agarwal OP. Radical cures of hydrocoele by Lord's method as compared with eversion of sac. Indian J Surg. 1983;45:329-31.

15. Effron G, Sharkey CG. The Lord's operation fro hydrocoele. Surg Gynaecol Obstet. 1967;125:603-6.

16. Dahl DS, Singh M, O'conor Vj Jr, Sokol JK, Bulkley GJ. Lord's operation compared with conventional techniques. Arch Surg. 1972;104:40-1.

17. Reddy. Lords operation for radical cure of hydrocoele. Indian J Surg. 1973;35:136-8.

18. Rai. Plication operation for hydrocoele. Indian J Surg. 1978;40:481-84.

Copyright: () the author(s), 2019. It is an open-access article distributed under the terms of the Creative Commons Attribution License (CC BY 4.0), which permits authors to retain ownership of the copyright for their content, and allow anyone to download, reuse, reprint, modify, distribute and/or copy the content as long as the original authors and source are cited.

How to cite this article: Singh J, Singh AP. Surgical Treatment of Cystic Swellings of Scrotum and its Management: A Clinico-Pathological Study. Asian J. Med. Res. 2019;8(2):SG11-SG14.

DOI: dx.doi.org/10.21276/ajmr.2019.8.2.SG3

Source of Support: Nil, Conflict of Interest: None declared. 